\title{
Friday the 13th: The Empirics of Bad Luck
}

\author{
Jan Fidrmuc and J. D. Tena*
}

\begin{abstract}
PHILLIP: Just figures with my luck. I was born on Friday the 13th... STEVEN: It's not gonna change a thing, Phillip. In fact, Friday the 13th's my lucky day. Jim Carrey as Steven and Ewan McGregor as Phillip in I Love You Phillip Morris (2009)
\end{abstract}

\section{INTRODUCTION}

Superstitions, or beliefs that one event or occurrence can cause another without the two being linked by any observable natural process, are very common phenomena, and some have been around for hundreds if not thousands of years. Examples include believing that bad luck can be brought about by walking under a ladder, seeing a black cat crossing one's path, opening an umbrella indoors, spilling salt or breaking a mirror. On the other hand, finding a horseshoe or a four-leaf clover or carrying a specific talisman or token in one's wallet or purse can supposedly bring luck and ward off evil. ${ }^{1}$ Associating some events with luck,

* Jan Fidrmuc Department of Economics and Finance and Centre for Economic Development and Institutions (CEDI), Brunel University; Institute of Economic Studies, Charles University; and CESifo Munich. Contact information: Department of Economics and Finance, Brunel University, Uxbridge, UB8 3PH, United Kingdom. E-mail: Jan.Fidrmuc@brunel.ac.uk or jan@fidrmuc.net. http:// www.fidrmuc.net/. Phone: +44-1895-266-528. J. D. Tena: Departamento de Estadística, Universidad Carlos III and Dipartimento di Scienze economiche e aziendali, Università di Sassari. Contact information: C/Madrid 126. 28903 Getafe (Madrid), Spain, E-mail: jtena@est-econ.uc3m.es. Phone: +34 916241259. We benefited from comments and suggestions by John Bennett, Ruxanda Berlinschi, Horst Feldmann, Sugata Ghosh, Pablo Guilen, Evžen Kočenda, Miguel Puchades, Martin Šuster and Ronald Wintrobe, as well as participants at the Bratislava Economic Meeting 2014, European Public Choice conference 2015 in Groningen, and seminar participants at Brunel University and ISET. We are grateful also to David Stadelmann as the editor in charge of this paper and to two anonymous referees for their constructive comments and advice.

The copyright line for this article was changed on 30 July 2015 after original online publication

1 Similarly, an extremely successful self-help book by Rhonda Byrne, The Secret, argues that one's thinking can have real effects: positive thinking brings about improvements in one's life, aggressive thoughts make one the target of aggression, and negative attitude results in adverse outcomes. The book sold more than 20 million copies and has been translated into 46 languages, despite absence of any evidence supporting its predictions. 
or the absence thereof, may have rational or practical origins. ${ }^{2}$ However, believing in lucky and unlucky numbers or days, despite being very wide-spread, seems devoid of any rational basis. For example, the number 13 is considered almost universally unlucky in the European culture and Friday the 13th, is seen as a particularly inauspicious day. ${ }^{3}$

Fudenberg and Levine (2006) formulate a game-theoretic model to show that some superstition can emerge even if people are rational. In particular, they argue that superstitions are more likely to be believed if they are further removed from the game equilibrium path. Moreover, rational people shape their behavior in response to such superstitious beliefs once these emerge. Similarly, Foster and Kokko (2009) show that superstitions can develop if the occurrence of the trigger event is occasionally associated with the predicted outcome and the payoff to that outcome is sufficiently large. ${ }^{4}$

Whether rational or not, superstitions can have important consequences. ${ }^{5}$ This is particularly the case with respect to beliefs in lucky and unlucky numbers. Hotels often do not have floors or rooms with 13 in the number, some airlines do not to have $13^{\text {th }}$ row in their planes and many airports do not have gate 13 . In the UK, 28 percent of all streets do not have a number 13, and houses with that number sell on average for $£ 6,500$ less than similar houses in the same street. ${ }^{6}$ Some people refuse to start new undertakings, make major purchases or decisions on a Friday the $13^{\text {th }}$, with some even refusing to leave their house. One estimate puts the loss of business on Friday the $13^{\text {th }}$ at around $\$ 1$ billion in the US. ${ }^{7}$ A recent report, similarly, found that flights on Friday the $13^{\text {th }}$ June 2014 were on considerably cheaper than flights on other days in that month in Austria, France, UK and Sweden. ${ }^{8}$

2. For example, mirrors and salt used to be valuable and therefore breaking a mirror or spilling salt may have been seen as a particularly outrageous example of waste. Walking under a ladder may invite injury due to falling objects. The superstition about black cats is sometimes attributed to the fact that horses could not see black cats during the night and would get startled when confronted with one.

3. There are various explanations for why Friday the $13^{\text {th }}$ is considered unlucky. Most commonly, it is attributed to the fact that Jesus was crucified on a Friday, which was preceded by the Last Supper attended by 13 diners, one of whom went on to betray Jesus.

4. As an example, the initial version of the present paper counted exactly 13 pages (single-spaced). It was rejected by five journals. The next version counted 16 pages ( 1.5 spaced) and was accepted with very minor changes. This could be interpreted as suggesting that the number 13 (or writing single-spaced papers) is causally associated with bad luck.

5. A well-known example was President Reagan who received advice from his astrologist on many issues, including on how to approach Mikhail Gorbachev when discussing global disarmament in Reykjavik in 1985. See "The president's stargazer," Obituary of Joan Quigley, The Economist, 8 November 2014).

6. See "Live at Number 13? Unlucky for you: Your house is worth $£ 6,500$ less than your neighbour's," http://www.dailymail.co.uk/news/article-2061317/Live-Number-13-Unlucky-Your-house-worth-6-500neighbours.html.

7. See "Friday the 13th Phobia Rooted in Ancient History," available at http://news.nationalgeographic. com/news/2004/02/0212_040212_friday13.html.

8. See "The cheapest day for flights? Today! Passengers told to ignore their Friday the 13th superstition to get the best travel deals," http://www.dailymail.co.uk/travel/article-2656020/The-cheapest-day-flightsToday-Passengers-told-ignore-Friday-13th-superstition-best-travel-KAYAK-data-shows-deal.html. 
A number of studies considered whether certain outcomes are systematically different on Friday the $13^{\text {th }}$. The effect on the stock market is either nill or may even be positive (although small, see Dyl and Maberly 1988; Coutts 1999; Lucey 2001; Dowling and Lucey 2005; and Chung, Darrat and Li, 2014). Friday the $13^{\text {th }}$, similarly, does not appear to be associated with more injuries or fatalities due to traffic accidents (Radun and Summala, 2004, based on comprehensive Finnish data spanning 1989-2002) or emergency hospital admissions (Lo et al., 2012, based on data from six US hospitals during 2002-06; interestingly, there was also no significant increase in emergency treatments due to psychiatric conditions on Fridays the $\left.13^{\text {th }}\right)$. Such research, however, can suffer from biases in people's behavior: superstitious people may behave differently on a day that they believe to be unlucky compared to a normal day. ${ }^{9}$ Kramer and Block (2008) report on a set of experiments in the US in which the subjects were asked to make risky decisions. The participants became significantly more risk averse on Friday the $13^{\text {th }}$. Damisch, Stoberock and Mussweiler (2010), similarly, find that evoking one's superstitious belief (for instance by keeping fingers crossed) improves the subsequent performance, which they interpret as evidence of the subjects' increased confidence.

Other cultures associate different days and numbers with bad luck. In the Chinese (and East Asian) culture, numbers 4 and 8 are associated with bad and good luck, respectively, because they sound similar in Chinese to the words meaning death and wealth, respectively. Fortin, Hill and Huang (2014), considering the American housing market, find that in areas with a large share of immigrants houses with the number ending in 4 sell for 2.2 percent less while those with numbers ending in 8 garner a 2.5 percent price premium. Similar results were obtained by Bourassa and Peng (1999) for regions in New Zealand with large Chinese populations and by Shum et al. 2014) for China. ${ }^{10}$ Travis et al. (2010) analyze the results of auctions of vehicle license plates in Hong Kong and find that the resulting prices depend on the numbers on the place. Hirshleifer et al. (2014) and Doucouliagos (2004) show that financial decisions in the stock market are significantly affected by superstitions and number preference in China and Australia, respectively. ${ }^{11}$

9. Indeed, one study finds that there are fewer accidents on a Friday the 13th as people tend to drive more carefully, see "Friday 13th not more unlucky, Dutch study shows," http://uk.reuters.com/article/2008/06/ 13/us-luck-idUKL1268660720080613.

10. Other examples include the Beijing Olympics, which started at 8:08 pm on 8/8/2008, or the ChineseAmerican journalist Jennifer 8 Lee who has chosen the number eight as her middle name (see http:// en.wikipedia.org/wiki/Jennifer_8._Lee).

11. Furthermore, Burma under the authoritarian rule of President Ne Win issued, in 1987, banknotes in the denominations of 45 and 90 kyats; this was because Ne Win considered the number 9 to be lucky (see Delisle 2009, p. 89). Despite this, Ne Win was overthrown in a coup on 8/8/1988 (the so-called 8888 Uprising), and that revolt in turn ended after the military staged a takeover on 18 September $(1+8=9$, or 99). See "Burma ruled by numbers," BBC, 3 October 2007, http://news.bbc.co.uk/1/hi/world/asiapacific/7025827.stm. 
In this paper, we examine the evidence on the effect of superstitions concerning the number 13 and Friday the $13^{\text {th }}$. Selecting the right kind of data is crucial for this purpose. Surveys may be unreliable because of hindsight bias: individuals are more likely to remember adverse outcomes that happened on an unlucky day than those that happened on other days. Setting up controlled experiments, as argued above, might result in data affected by changes in subject's behavior or confidence. We therefore consider the effect of being born on an unlucky day: on the $13^{\text {th }}$, or on a Friday the $13^{\text {th }}$.

In focusing on the timing of birth, our approach is similar to the work of Wong and Yung (2005) and Do and Phung (2010) who use the fact that the Chinese and Vietnamese consider certain years auspicious. Indeed, in both China and Vietnam, significantly more children are born during years that are thought to be lucky. Wong and Yung (2005) find no effect of being born in the Year of the Dragon for Chinese children. Do and Phung (2010) find that Vietnamese children born during auspicious years do better in later life. The latter study, however, attributes this effect to how much the parents care about the future of their children: planned children are more likely to both be born during a lucky year and also receive more parental investment.

To identify the people potentially subject to bad luck, we use the UK Labor Force Survey, with information on the precise date of birth of almost 4 million individuals. While it is relatively easy to ensure that one's child is born during a lucky year, the day of birth is, in most cases, as good as random. We therefore consider whether those born on the $13^{\text {th }}$ and on Friday the $13^{\text {th }}$ are more or less likely to be employed, whether they have higher or lower wages, and whether they are more or less likely to remain single. These are important outcomes that have large effects on one's quality of life, yet they cannot be easily affected by short-term behavioral adjustments.

There is a number of possible ways how being born on an inauspicious day might affect one's life-time outcomes. First, it may indeed be the case that some supranatural force endows those born on an unlucky day with less (or more) luck. Second, even without such a mysterious mechanism at work, believing in events that bring bad/good luck can affect one's behavior and confidence sufficiently to have an effect. Finally, one's date of birth is often known to others - friends, family, employers or spouses (both potential and actual) - who may adjust their behavior and discriminate, positively or negatively, in their actions towards such individuals. In the second and third case, whatever effect we might observe would be driven mainly by psychology. In this, the effect of being born on a particular day might be similar to the effect of having a particular name: some people believe strongly that having the right name is an important determinant of one's fortunes. ${ }^{12}$

In the next section, we present the data used, before discussing our methodology and the results in section 3. The final section summarizes our findings and offers some conclusions.

12. Some of the well-known examples include two brothers called Winner Lane and Loser Lane, and a woman named Marijuana Pepsi Sawyer. Loser Lane and Marijuana Pepsi Sawyer did well while Winner Lane ended up as a career criminal. 


\section{DATA}

We investigate the issue at hand using the UK Labor Force Survey (LFS), a quarterly nationally-representative survey of households across the UK. Each quarter, the Office for National Statistics (ONS) interviews approximately 60 thousand households, with over 100 thousand individual respondents aged 16 and above. We use data from 1999 to 2011, which gives us around 3.9 million observations.

The survey contains detailed demographic and socio-economic information about the respondents, including their labor-market outcomes, marital status, and the date of birth. ${ }^{13}$ We identify the individuals born on the $13^{\text {th }}$ and compare their outcomes with the rest of the sample. As robustness checks, we also perform falsification (placebo) tests, whereby we consider those born on the $12^{\text {th }}$ and $14^{\text {th }}$. The individuals born on these three consecutive days should be very similar to each other. Indeed, for natural births, which of these three days one is born on should be essentially random. Therefore, if being born on the $13^{\text {th }}$ has an effect on one's outcomes, such an effect should be only observed for those actually born on that day and not for those born one day earlier or later. On the other hand, if the individuals born on the $13^{\text {th }}$ are subject to some sort of mid-month effect (we are not aware why any such effect should be present but cannot exclude it), then those born on the $12^{\text {th }}$ and $14^{\text {th }}$ would be presumably also affected by it. Finally, we identify those individuals who were born on a Friday the $13^{\text {th }}$ and consider their outcomes as well.

Given the large number of observations, we have rather a lot of treated individuals: 122,883 were born on the $13^{\text {th }}$. This is slightly lower than the number of those born either on the $12^{\text {th }}$ and $14^{\text {th }}: 125,476$ and 123,206 , respectively. The fact that fewer people in our dataset were born on the $13^{\text {th }}$ is not too surprising: some births - caesarean sections and induced deliveries - are scheduled and superstitious parents and/or obstetricians may prefer not to have them on an inauspicious day. ${ }^{14}$ Nevertheless, the number of people born on the $13^{\text {th }}$ is not out of line with the distribution of births across all days of the month, as Figure 1 demonstrates. ${ }^{15}$ In fact, there are several other days (such as the $8^{\text {th }}$ and $9^{\text {th }}$ ) with fewer births than the $13^{\text {th }}$. Therefore, it seems unlikely that expectant parents go

13. The date of birth is not available in the publicly released LFS datasets. We are grateful to the Office for National Statistics for giving us access to the restricted release of the LFS.

14. The share of ceasareans has been rising in the UK, from 12 percent in 1990 to 24 percent in 2008 (see Focus on ceasarean section, NHS Institute for Innovation and Improvement, 2009). This is lower than in the US where around one in three deliveries is by c-section.

15. We have no explanation for the relatively high numbers of respondents born on the 1 st and 15 th. One possibility is that this may reflect some peculiar aspect of how the UK National Health Service if funded, whereby it may be advantageous for hospitals to schedule planned births at the beginning and middle of a month. The fact that children born on $1^{\text {st }}$ September start school one year later than those born on $31^{\text {st }}$ of August can explain the first of the two spikes. Another possibility is that this is due to misreporting by respondents. 
Figure 1

Distribution of dates of birth by day

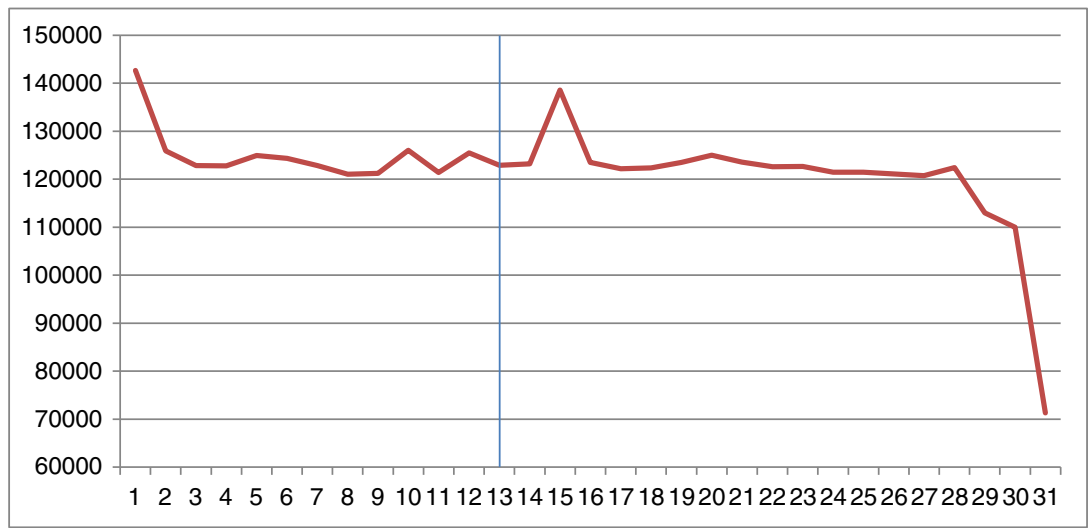

out of their way to avoid having a child born on an unlucky day. Finally, we observe 18,032 individuals born on Fridays the $13^{\text {th }}$.

\section{BORN (UN)LUCKY?}

We start with a descriptive analysis of raw data for the three outcomes of interest - employment, hourly wage and marriage - comparing the individuals born on unlucky days with the rest of sample. Figure 2 presents the average probability of being employed, average hourly wage and average probability of being single for the individuals born on the $13^{\text {th }}$ and on Friday the $13^{\text {th }}$ as well as for the remaining individuals. The diamonds depict the mean values while the vertical lines capture the 95 percent confidence intervals. The latter are relatively wide for the individuals born on the $13^{\text {th }}$ and Friday the $13^{\text {th }}$ and narrow for the rest of the sample; this is because standard deviations depend inversely on the number of observations. In general, being born on an unlucky day does not seem to be associated with dramatically different outcomes, although individuals born on either unlucky day have a slightly higher employment probability, and those born on Friday the $13^{\text {th }}$ have a lower hourly wage and are also more likely to be single. The differences are not particularly large and may be driven by the socioeconomic characteristics of these individual. Indeed, given that different years have different numbers of Fridays the $13^{\text {th }}$ (between one and three), it is possible for birth on this day to be correlated with age, the business cycle or other relevant outcomes.

It is therefore more informative to consider the three outcomes of interest after controlling for individual socio-economic characteristics by means of regression analysis instead of merely comparing average values. The results for the probability of employment (we do not distinguish between full-time and part-time employment) are 
Figure 2

Mean outcomes, individuals born on unlucky days vs the rest of sample

Average Employment Probability \& 95\% Confidence Intervals.

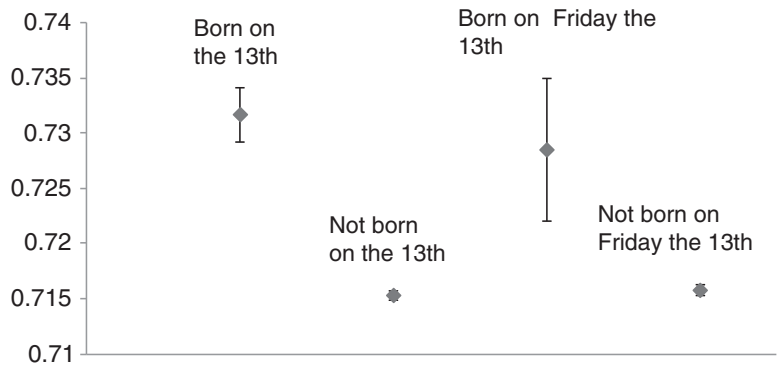

Average Hourly Wage \& 95\% Confidence Intervals.

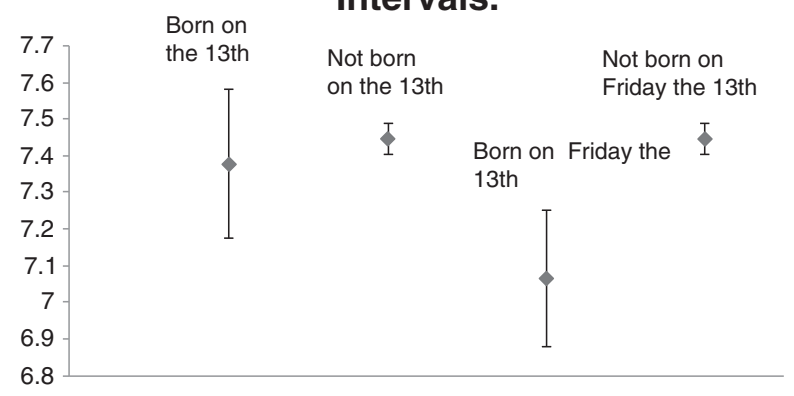

Average Probability of Being Single and 95\% Confidence Intervals.

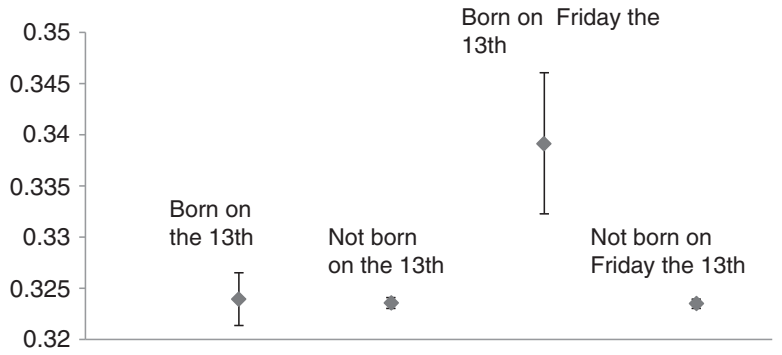

summarized in Table 1 . We present only the coefficient estimates for the birth-day dummy, although the regressions include a broad array of standard socio-economic controls: highest attained qualification, occupation, being an apprentice, ethnicity, regional dummies and dummies for the quarter of birth. As is standard in analyses of 
JAN FIDRMUC/J. D. TENA

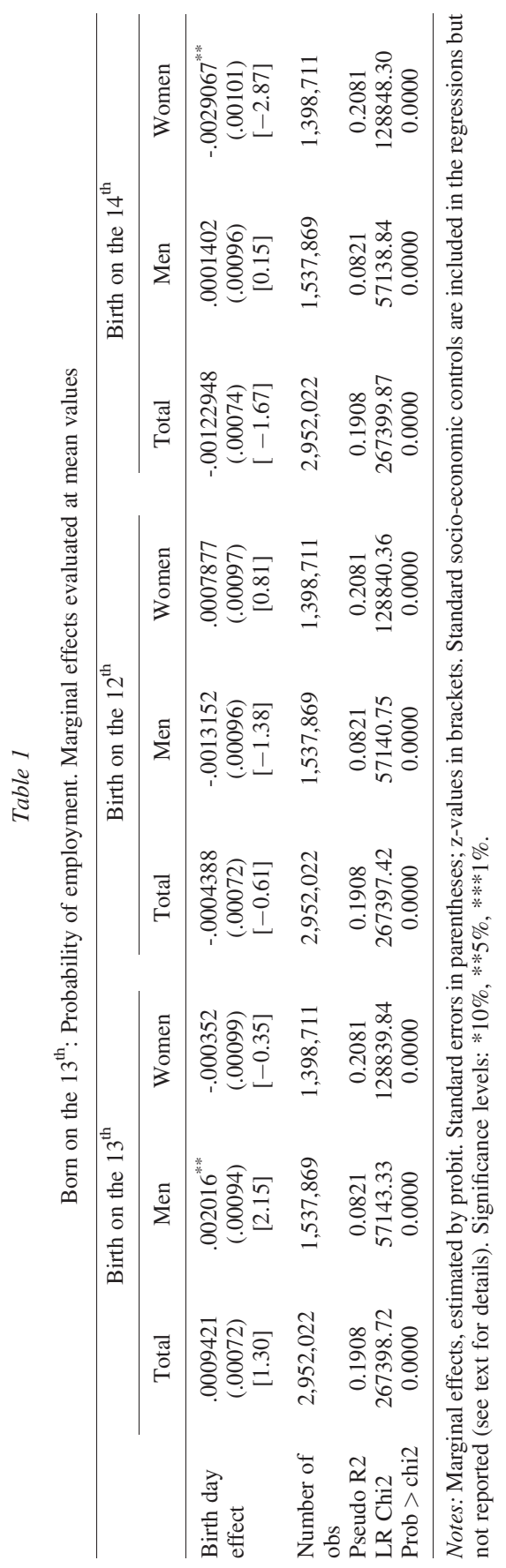


labor-market outcomes, we run separate regressions for males and females (when we do not, we include a gender dummy in the regression). The results indicate that among those born on the $13^{\text {th }}$, males are somewhat more likely to be employed. On the other hand, we find a negative effect for females born on the $14^{\text {th }}$. We are reluctant to assign much weight to either of these results as the estimated effects are very small (the probability of employment is higher by 0.2 percentage point for men born on the $13^{\text {th }}$ and 0.3 percentage point lower for women born on the $\left.14^{\text {th }}\right)$. In general, it is easy to obtain small but significant coefficients with a large number of observations: our results are perhaps more remarkable for how small the estimated z-values are, given how many observations we include in our analysis. Nevertheless, it is reassuring that, if any, the effect of being born on the $13^{\text {th }}$ is positive rather than negative.

Next, we consider the effect on wages in Table 2. These regressions are estimated by OLS and again include a wide range of controls. ${ }^{16}$ None of the estimated effects for those born on the $13^{\text {th }}$ is significantly different from zero. Table 3 repeats the exercise for white-collar and blue-collar occupations (rather than males and females). Again, none of the birth effects is significant.

As a final test of being born on the $13^{\text {th }}$, we consider marital outcomes. Table 4 reports the results of probit regressions of the probability of being single (again, accounting for standard controls, including age, which is likely to be particularly important in this case). We consider being single as potentially more indicative of luck (or its absence) than the relatively subtle differences between being married vs cohabitating, or distinguishing those who are married from those who married but subsequently became divorced, separated or widowed. A number of coefficients are now negative and significant: for males born on the $13^{\text {th }}$, but also for females (and males and females together) born on the $14^{\text {th }}$. Given that we seem to obtain similar results for the treatment effect and for (some of) the falsification tests, we are again reluctant to assign much weight to this result. As before, even when significant, the estimated effects are very small: men born on the $13^{\text {th }}$ are 0.7 percentage point less likely to remain single.

Next, we consider the much smaller number of individuals born on Friday the $13^{\text {th }}$. Such unlucky days occur relatively frequently: each calendar year has to have at least one and it is quite common for two or even three to fall within the same year. ${ }^{17}$ Table 5 shows that being born on Friday the $13^{\text {th }}$ has no impact on the probability of employment. In Table 6, we see that being born on Friday the $13^{\text {th }}$ has no effect on the hourly wage. Finally, Table 7 shows that, unlike when born on the $13^{\text {th }}$, there might be a small positive effect of being born on

16. The number of observations is much lower than for employment for two reasons. First, wage information is not collected from the LFS respondents in every wave (each individual in included in the survey for five consecutive waves), unlike employment status. Second, wages are only reported for those who are employed and not for the unemployed and those out of the labor force.

17. 2014 had one Friday the 13th, in June, whereas three such days occur during 2015: in February, March and November. 


\section{JAN FIDRMUC/J. D. TENA}

Table 2

Born on the $13^{\text {th }}$ : Wage (by gender)

\begin{tabular}{|c|c|c|c|c|c|c|c|c|c|}
\hline & \multicolumn{3}{|c|}{ Birth on the $13^{\text {th }}$} & \multicolumn{3}{|c|}{ Birth on the $12^{\text {th }}$} & \multicolumn{3}{|c|}{ Birth on the $14^{\text {th }}$} \\
\hline & Total & Men & Women & Total & Men & Women & Total & Men & Women \\
\hline \multirow[t]{2}{*}{ Birth day effect } & $\begin{array}{l}-.066 \\
(.117)\end{array}$ & $\begin{array}{l}.144 \\
(.206)\end{array}$ & $\begin{array}{l}-.196 \\
(.135)\end{array}$ & $\begin{array}{l}.1435 \\
(.1169)\end{array}$ & $\begin{array}{l}.3443 \\
.(204)\end{array}$ & $\begin{array}{l}-.0111 \\
(.1368)\end{array}$ & $\begin{array}{c}-0.0037 \\
(.1175)\end{array}$ & $\begin{array}{c}-0.1968 \\
(.2085)\end{array}$ & .14 \\
\hline & {$[-0.57]$} & {$[0.70]$} & {$[-1.45]$} & [1.23] & {$[1.68]$} & {$[-0.08]$} & {$[-0.03]$} & {$[-0.94]$} & [1.07] \\
\hline Numl & 258117 & 106990 & 151127 & 258117 & 106990 & 151127 & 258117 & 106990 & 151127 \\
\hline Adj R & 0.0342 & 0.03 & 0. & 0.0342 & 0.03 & 0.0 & 0.0 & 0.0318 & 0.0405 \\
\hline $\mathrm{F}$ & 183.59 & 74.18 & 131.36 & 183.62 & 74.23 & 131.32 & 183.58 & 74.19 & 131.34 \\
\hline Prob $>$ & 0.0000 & 0.0000 & 0.0000 & 0.0000 & 0.0000 & 0.0000 & 0.0000 & 0.0000 & 0.0000 \\
\hline
\end{tabular}

Notes: Standard errors in parentheses; t-values in brackets. Standard socio-economic controls are included in the regressions but not reported (see text for details). Significance levels: *10\%, **5\%,***1\%.

Table 3

Born on the $13^{\text {th }}:$ Wage (by occupation)

\begin{tabular}{|c|c|c|c|c|c|c|c|c|c|}
\hline & \multicolumn{3}{|c|}{ Birth on the $13^{\text {th }}$} & \multicolumn{3}{|c|}{ Birth on the $12^{\mathrm{t},}$} & \multicolumn{3}{|c|}{ Birth on the $14^{\text {th }}$} \\
\hline & Total & $\begin{array}{l}\text { Blue } \\
\text { collar }\end{array}$ & $\begin{array}{l}\text { White } \\
\text { collar }\end{array}$ & Total & $\begin{array}{l}\text { Blue collar } \\
\text { worker }\end{array}$ & $\begin{array}{l}\text { White } \\
\text { collar }\end{array}$ & Total & $\begin{array}{l}\text { Blue collar } \\
\text { worker }\end{array}$ & $\begin{array}{l}\text { White } \\
\text { collar }\end{array}$ \\
\hline $\begin{array}{l}\text { Birth on the } \\
13^{\text {th }}\end{array}$ & $\begin{array}{c}-.066 \\
(.117) \\
{[-0.57]}\end{array}$ & $\begin{array}{c}-.26462 \\
(.3327) \\
{[-0.80]}\end{array}$ & $\begin{array}{c}-.21069 \\
(.3852) \\
{[-0.55]}\end{array}$ & $\begin{array}{c}.1435 \\
(.1169) \\
{[1.23]}\end{array}$ & $\begin{array}{l}0.6226 \\
(.3292) \\
{[1.89]}\end{array}$ & $\begin{array}{l}-.1073 \\
(.3818) \\
{[-0.28]}\end{array}$ & $\begin{array}{c}-0.0037 \\
(.1175) \\
{[-0.03]}\end{array}$ & $\begin{array}{l}-.0756 \\
(.3268) \\
{[-0.23]}\end{array}$ & $\begin{array}{c}-.0568 \\
(.3954) \\
{[-0.14}\end{array}$ \\
\hline $\begin{array}{l}\text { Number of } \\
\text { obs }\end{array}$ & 258117 & 34074 & 16247 & 258117 & 34074 & 16247 & 258117 & 34074 & 16247 \\
\hline Adj R2 & 0.0342 & 0.0644 & 0.0525 & 0.0342 & 0.06 & 0.0525 & 0.0342 & 0.0 & 0.0525 \\
\hline . & & & & & & & & & \\
\hline Prob $>F$ & 0.0000 & 0.0000 & 0.0000 & 0.0000 & 0.0000 & 0.0000 & 0.0000 & 0.0000 & 0.0000 \\
\hline
\end{tabular}

Notes: Standard errors in parentheses; t-values in brackets. Standard socio-economic controls are included in the regressions but not reported (see text for details). Significance levels: * $10 \%$, ** 5\%, ***1\%.

Friday the $13^{\text {th }}$ on the probability of remaining single. This time, the effect appears for both genders when analyzed together, and for females when the two genders are considered separately. Again, the effect is rather small: women born on this unlucky day are less than 1 percent more likely to remain single than other women; men born on Friday the $13^{\text {th }}$ are not any more or less likely to remain single than other men.

Figure 3 summarizes these findings: it depicts the effect of being born on the $13^{\text {th }}$ or on Friday the $13^{\text {th }}$ on the probability of employment, hourly wage and being single (for both genders considered together). In each graph, the diamond represents the marginal effect (coefficient estimate in case of wages) associated with birth on an unlucky day while the vertical lines again capture the corresponding 95 percent confidence intervals. If the confidence interval includes the zero, then the individuals born on unlucky days do not experience different outcomes than individuals born on other days. As is clear from the figures, only 
FRIDAY THE 13TH

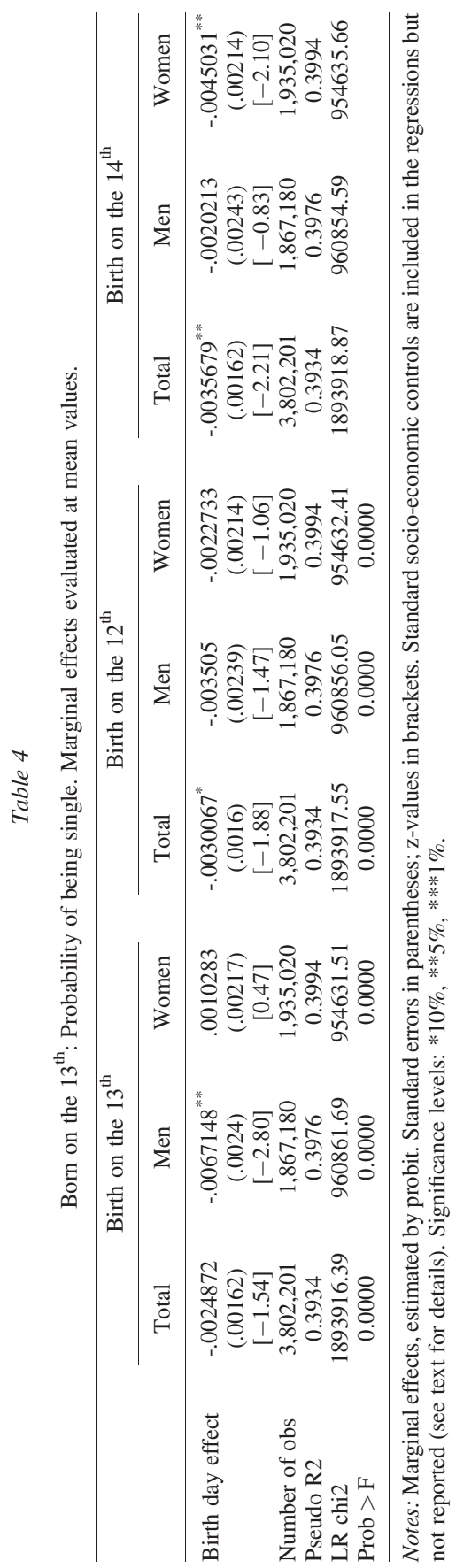




\section{JAN FIDRMUC/J. D. TENA}

Table 5

Born on Friday the $13^{\text {th }}$ : Probability of employment. Marginal effects evaluated at mean values

\begin{tabular}{lccc}
\hline & \multicolumn{3}{c}{ Birth on Friday the $13^{\text {th }}$} \\
\cline { 2 - 4 } & Total & Men & Women \\
\hline Birth day effect & -.00090 & -.0000888 & -.0015747 \\
& $(.00189)$ & $(.00246)$ & $(.00257)$ \\
& {$[-0.48]$} & {$[-0.04]$} & {$[-0.61]$} \\
Number of obs & $2,952,022$ & $1,537,869$ & $1,398,711$ \\
Pseudo R2 & 0.1908 & 0.0821 & 0.2081 \\
LR Chi2 & 267397.28 & 57138.82 & 128840.10 \\
Prob $>$ chi2 & 0.0000 & 0.0000 & 0.0000 \\
\hline
\end{tabular}

Notes: Marginal effects, estimated by probit. Standard errors in parentheses; z-values in brackets. Standard socio-economic controls are included in the regressions but not reported (see text for details). Significance levels: $* 10 \%, * * 5 \%, * * * 1 \%$.

Table 6

Born on Friday the $13^{\text {th }}$ : Wage

\begin{tabular}{lccccc}
\hline & \multicolumn{5}{c}{ Birth on Friday the $13^{\text {th }}$} \\
\cline { 2 - 6 } & Total & Men & Women & Blue collar & White collar \\
\hline Birth day effect & -.3032 & -.5231 & -.0821 & -.4704 & -.5164 \\
& $(.3061)$ & $(.5586)$ & $(.3480)$ & $(0.853)$ & $(0.9653)$ \\
& {$[-0.99]$} & {$[-0.94]$} & {$[-0.24]$} & {$[-0.55]$} & {$[-0.53]$} \\
Number of obs & 258117 & 106990 & 151127 & 34074 & 16247 \\
Adj R2 & 0.0342 & 0.0318 & 0.0405 & 0.0632 & 0.0525 \\
F & 183.61 & 74.19 & 131.32 & 50.59 & 22.45 \\
Prob > F & 0.0000 & 0.0000 & 0.0000 & 0.0000 & 0.0000 \\
\hline
\end{tabular}

Notes: Standard errors in parentheses; t-values in brackets. Standard socio-economic controls are included in the regressions but not reported (see text for details). Significance levels: * $10 \%$, ** 5\%, $* * * 1 \%$.

being born on Friday the $13^{\text {th }}$ is associated with a slightly higher probability of remaining single (with this effect being just about significant at the 5 percent level); all of the remaining outcomes are not different for the individuals born on unlucky days and the rest of sample.

So far, we considered birth on the $13^{\text {th }}$ relative to being born on any other day, and compared the results with being born on the $12^{\text {th }}$ or $14^{\text {th }}$ (the so-called falsification or placebo tests). The objective was to compare the results obtained for the individuals born on an unlucky day with the results for individuals whose day of birth is not considered unlucky. Next, we consider only the individuals born on these three days. The results are summarized in Table 8 (for both genders together): the first three columns consider those born on the $13^{\text {th }}$ while the next three columns report the estimates for those born on Friday the $13^{\text {th }}$, in both cases 


\section{Table 7}

Born on Friday the $13^{\text {th }}$ : Probability of being single. Marginal effects evaluated at mean values

\begin{tabular}{lccc}
\hline & \multicolumn{3}{c}{ Birth on Friday the $13^{\text {th }}$} \\
\cline { 2 - 4 } & Total & Men & Women \\
\hline Birth day effect & $.0082634^{* *}$ & .00801 & $.0092068^{*}$ \\
& $(.00421)$ & $(.00627)$ & $(.00564)$ \\
& {$[1.96]$} & {$[1.28]$} & {$[1.63]$} \\
Number of obs & $3,802,201$ & $1,867,180$ & $1,935,020$ \\
Pseudo R2 & 0.3934 & 0.3976 & 0.3994 \\
LR chi2 & 1893917.92 & 960855.55 & 954633.98 \\
Prob $>$ F & 0.0000 & 0.0000 & 0.0000 \\
\hline
\end{tabular}

Notes: Marginal effects, estimated by probit. Standard errors in parentheses; z-values in brackets. Standard socio-economic controls are included in the regressions but not reported (see text for details). Significance levels: $* 10 \%, * * 5 \%, * * * 1 \%$.

compared to those born on the $12^{\text {th }}$ and $14^{\text {th }} .{ }^{18}$ The findings of this analysis are very much in line with our previous results. In particular, we observe a significant but very small positive effect of being born on the $13^{\text {th }}$ on the probability of employment: such individuals are 0.2 percent more likely to be employed than those born on the $12^{\text {th }}$ or $14^{\text {th }}$. We again find that individuals born on Friday the $13^{\text {th }}$ are slightly more likely to remain single: 1.2 percent more likely than their counterparts born on the $12^{\text {th }}$ or $14^{\text {th }}$.

Finally, as an additional robustness test we consider the matching estimator developed by Abadie and Imbens (2006), including their bias-corrected matching estimator. Although, in principle, it is reasonable to think that birthdays are randomly assigned within the sample, this assumption can be violated in some cases. A simple regression that includes a set of relevant control variables can be used to deal with this potential endogeneity problem as is the case with the results shown in Tables 1 to 7. However, as argued by Morgan and Winship (2007), the regression approach can be subject to two important drawbacks. The first relates to the fact that the causal effect of being born on the $13^{\text {th }}$ is not necessarily constant over all individuals. In this cases, the estimated causal effect represents a conditional-variance-weighted average of individual causal effects and the causal estimation is only unbiased and consistent for this particularly weighted average that is not usually the parameter of interest. The second problem with the regression strategy relates to the fact that the probability of being treated should be uncorrelated with the error term. This, in turn, depends

18. The reference category for birth on Friday the $13^{\text {th }}$ is the same as for birth on the $13^{\text {th }}$ : those born on the $12^{\text {th }}$ and $14^{\text {th }}$, regardless of the day of the week. Considering the day of the week when assessing the birth on Friday the $13^{\text {th }}$ would reduce the number of observations considerably. Moreover, it is not obvious whether the reference group in that case should be those born on Friday the $12^{\text {th }} / 14^{\text {th }}$, or Thursday the $12^{\text {th }}$ and Saturday the $14^{\text {th }}$. 
JAN FIDRMUC/J. D. TENA

Figure 3

Effect of being born on unlucky days

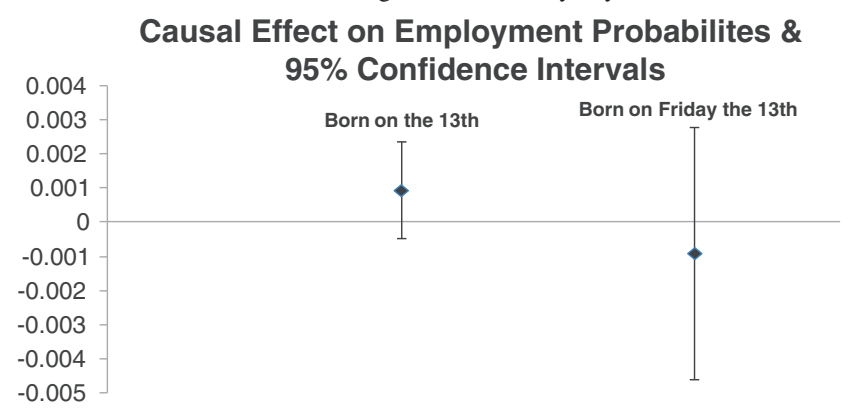

Causal Effect on Hourly Wages \& 95\%

Confidence Intervals

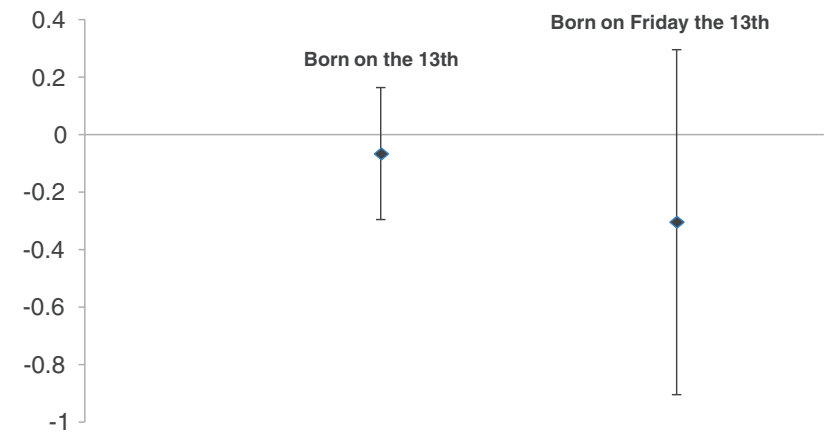

Causal Effect on the Probability of Being Single \& $95 \%$ Confidence Intervals

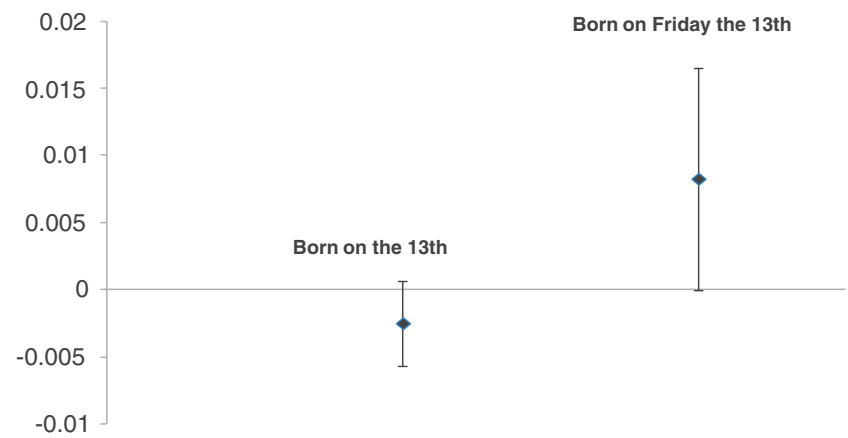

on the specification of the covariates. Therefore, in order to interpret the estimation of a regression strategy as a real causal effect, we require a fully flexible parameterization of $X$. 


\section{FRIDAY THE $13 \mathrm{TH}$}

\section{Table 8}

Effect on the probability of being married and employed: Birth on unlucky day vs being born on $12^{\text {th }}$ or $14^{\text {th }}$

\begin{tabular}{lcccccccc}
\hline & \multicolumn{3}{c}{ Born on the $13^{\text {th }}$} & & \multicolumn{3}{c}{ Born on Friday the $13^{\text {th }}$} \\
\cline { 2 - 3 } & Single & Employed & Wage & & Single & Employed & Wage \\
\hline Birth day effect & .0008 & $0.002^{* *}$ & -.126 & & $.012^{* * * *}$ & -0.0006 & -.342 \\
& $(.002)$ & $(.0008)$ & $(.150)$ & & $(.0043)$ & $(0.002)$ & $(.333)$ \\
& {$[0.43]$} & {$[2.00]$} & {$[-0.84]$} & {$[2.71]$} & {$[-0.36]$} & {$[-1.03]$} \\
Number of observations & 371425 & 286134 & 25462 & & 371425 & 286134 & 25462 \\
Pseudo R2 & 0.3967 & 0.0796 & & & 0.3967 & 0.0796 & \\
LR chi2 & 185812.44 & 9572.06 & & & 185819.71 & 9568.21 & \\
Adj R2 & & & 0.0315 & & & & 0.0316 \\
F & & & 18.28 & & & & 18.28 \\
Prob $>$ chi2 (F) & 0.0000 & 0.0000 & 0.0000 & & 0.0000 & 0.0000 & 0.0000 \\
\hline
\end{tabular}

Notes: Standard errors in parentheses; z-values (t-values for wages) in brackets. Standard socio-economic controls are included in the regressions but not reported (see text for details). Significance levels: $* 10 \%, * * 5 \%, * * * 1 \%$. Marginal effects evaluated at mean values.

\section{Table 9}

Born on the $13^{\text {th }}$ and on Friday the $13^{\text {th }}$ : Matching approach

\begin{tabular}{lcc}
\hline Birth day effect on & Birth on the $13^{\text {th }}$ & Birth on Friday the $13^{\text {th }}$ \\
\hline Employment & .001784503 & .000569111 \\
& $(.002969413)$ & $(.003053289)$ \\
Number of obs & {$[0.60]$} & {$[0.19]$} \\
Hourly wage & $2,952,022$ & $2,952,012$ \\
& .014812172 & -.121767635 \\
Number of obs & $.178562015)$ & $(.145375928)$ \\
Being single & {$[0.08]$} & {$[-0.84]$} \\
& 258,117 & .006989903 \\
& .002247008 & $(.005125805)$ \\
Number of obs & $.004667413)$ & {$[1.36]$} \\
& {$[0.48]$} & $3,802,155$
\end{tabular}

Notes: Matching by propensity score. Standard errors in parentheses; t-statistics in brackets. Significance levels: * $10 \%, * * 5 \%, * * * 1 \%$.

To explain the matching estimation procedure, let $Y_{i}(1)$ and $Y_{i}(0)$ denote a given outcome, i.e. employment, wage or remaining single, for an individual $i$ if born on the treatment day and on any other day, respectively. If both $Y_{i}(1)$ and $Y_{i}(0)$ were observable, the effect of the treatment would be obtained as $Y i$ (1) $-Y i(0)$ and we could use this to estimate the causal effect of being born on the $13^{\text {th }}$ or Friday the $13^{\text {th }}$. However, for people born on the $13^{\text {th }}$, only $Y_{i}(1)$ is observable while only $Y_{i}(0)$ is observable for everyone else. Hence, in order to estimate the average treatment effect, we need to estimate the unobserved potential outcome for each person born the $13^{\text {th }}$ (or Friday the $13^{\text {th }}$ ). We can use the average outcome of similar individuals born on any other days to estimate the 
untreated outcome, $Y_{i}(0)$. Therefore, the matching estimator imputes the missing outcome by finding individuals similar to those born on the treatment day, based on the observed socio-economic characteristics.

As it is typical in this context, we assume the strong ignorability condition to ensure that the matching estimators identify and consistently estimate the treatment effect of interest. In particular, we assume that the assignment to treatment is independent of the outcomes conditional on the covariates and the probability of assignment is bounded away from zero and one. In other words, this amounts to saying that the assignment of the birth rate is "purely random" for similar individuals and that we can identify the effect of being born on the treatment day for each individual. Finally, the matching proceeds by propensity score that accounts for the effect of all control variables.

The results of this robustness check are reported in Table 9, again for the probability of being employed, the hourly wage, and the probability of remaining single. We only report the results for those born on the $13^{\text {th }}$ and Friday the $13^{\text {th }}$ and not for any other dates (falsification tests). Note also that we do not report separate estimates for males and females, as gender is part of the matching process. Importantly, and in line with our previous findings, neither being born on the $13^{\text {th }}$ not being born on Friday the $13^{\text {th }}$ has any significant effect on any of the outcomes considered.

\section{CONCLUSIONS}

In this paper, we take superstitions seriously. To this effect, we consider an occurrence which, for the most part, results from what is essentially a random draw: being born on an unlucky day, the $13^{\text {th }}$ or the Friday the $13^{\text {th }}$. We analyze the effect of birth on an inauspicious day on three outcomes that are of considerable impact for one's wellbeing: the probability of being employed, the hourly wage, and the probability of remaining single.

We find little evidence that being born on either the $13^{\text {th }}$ or on Friday the $13^{\text {th }}$ is associated with dramatically worse outcomes in the labor or marriage markets. Our results indicate a small increase in the probability that men born on the $13^{\text {th }}$ are employed and a small fall in the probability that they remain single (we leave it up to the reader to decide whether staying single is good or bad luck). We find similar effects of being born on the $12^{\text {th }}$ or $14^{\text {th }}$, our falsification tests, although neither of these dates is believed to be particularly auspicious or inauspicious. We also obtain a small positive and significant effect of being born on Friday the $13^{\text {th }}$ on the probability of being single. All of the significant effects are too small to be meaningful, let alone life-changing. Most likely, the significant coefficients are attributable to the large number of observations included in our 
analysis, which makes it easy to get small but significant coefficients: the t-values (z-values) that we estimate are surprisingly small, given the large number of observations. Overall, these results suggest that those born on the $13^{\text {th }}$, or on a Friday the $13^{\text {th }}$, need not lose much sleep over the inauspicious circumstances of their birth.

\section{REFERENCES}

Abadie, A. and G.W. Imbens (2006). Large Sample Properties of Matching Estimators for Average Treatment Effects, Econometrica. 74(1): 235-267.

Bourassa, S. C. and V. S. Peng (1999). Hedonic Prices and House Numbers: the Influence of Feng Shui. International Real Estate Review. 2(1): 79-93.

Coutts, J. A. (1999). Friday the thirteenth and the Financial Times Industrial Ordinary Shares Index 1935-94. Applied Economics Letters. 6(1): 35-37.

Chung, R., A. F. Darrat and B. Li (2014). Superstitions and stock trading: some new evidence. Journal of the Asia Pacific Economy. 19(4): 527-538.

Damisch, L., B. Stoberock and T. Mussweiler (2010). Keep Your Fingers Crossed! How Superstition Improves Performance. Psychological Science. 21(7): 1014-1020.

Delisle, G. (2009). Burma Chronicles. London: Jonathan Cape.

Do, Quy-Toan and Tung D. Phung (2010). The importance of Being Wanted. American Economic Journal: Applied Economics. 2(4): 236-53.

Doucouliagos, H. C. (2004). Number Preference in Australian Stocks. Applied Financial Economics. 14(1): 43-54.

Dowling, M. and B.M. Lucey (2005). Weather, biorhythms, beliefs and stock returns: Some preliminary Irish evidence. International Review of Financial Analysis. 14: 337- 355.

Dyl E. and E. Maberly (1988). The anomaly that isn't there: a comment on Friday the thirteenth. Journal of Finance. 43: 1285-1286.

Fortin, N., A. J. Hill and J. Huang (2014). Superstition in the Housing Market. Economic Inquiry. 52 (3): 974-993.

Foster, K.R. and H. Kokko (2009). The evolution of superstitious and superstition-like behavior. Proceedings of the Royal Society B. 276: 31-37.

Fudenberg, D. and D. K. Levine (2006). Superstition and Rational Learning. American Economic Review. 96(3): 630-651.

Hirshleifer, David and Jian, Ming and Zhang, Huai (2014). Superstition and financial decision making. MPRA_paper_58620.

Kramer, T. and L. Block (2008). Conscious and Nonconscious Components of Superstitious Beliefs in Judgment and Decision Making. Journal of Consumer Research. 34(6): 783-793.

Lo, B. M., C. M. Visintainer, H. A. Best and H. A. Beydoun (2012). Answering the myth: use of emergency services on Friday the $13^{\text {th }}$. American Journal of Emergency Medicine. 30: $886-889$.

Lucey, B. M. (2001). Friday the 13th: International evidence. Applied Economics Letters. 8(9): $577-579$.

Morgan, S. L. and C. Winship (2007). Counterfactuals and Causal Inference: Methods and Principles for Social Research. Cambridge: Cambridge University Press.

Radun, I. and H. Summala (2004). Females do not have more injury road accidents on Friday the $13^{\text {th }}$. BMC Public Health. 4: 54.

Shum, M., S. Wei and Y. Guangliang (2014). Superstition and "lucky" apartments: Evidence from transaction-level. Journal of Comparative Economics. 42(1): 109-117. 


\section{JAN FIDRMUC/J. D. TENA}

Travis Ng, Terence Chong and Xin Du (2010). The value of superstition. Journal of Economic Psychology. 31: 293-309.

Wong, K-F and L, Yung (2005). Do Dragon Have Better Fate? Economic Inquiry. 43(3): 689-697.

\section{SUMMARY}

We use the UK Labor Force survey to investigate whether the socio-economic outcomes of people born on the $13^{\text {th }}$ day of the month, and of those born on Friday the $13^{\text {th }}$, differ from the outcomes of people born on more auspicious days. In many European countries, including the UK, number 13 is considered unlucky and Friday the $13^{\text {th }}$ is seen as an especially unlucky day. We find little evidence that people born on the $13^{\text {th }}$ or those born on Friday the $13^{\text {th }}$ are significantly less likely to be employed, earn lower wages or that they are more likely to stay unmarried compared to people born on other days. 